\title{
Enhanced adsorption of oxytetracycline to weathered microplastic polystyrene: Kinetics, isotherms and influencing factors ${ }^{i s}$
}

\author{
Haibo Zhang ${ }^{\text {a, }}$, Jiaqing Wang ${ }^{a}$, Bianying Zhou ${ }^{a}$, Yang Zhou ${ }^{c}$, Zhenfei Dai ${ }^{c}$, Qian Zhou ${ }^{c}$, \\ Peter Chriestie ${ }^{\mathrm{b}}$, Yongming Luo ${ }^{\mathrm{b}}$ \\ a School of Environment and Resources, Zhejiang Agriculture and Forestry University, Hangzhou, 311300, China \\ ${ }^{\mathrm{b}}$ Nanjing Institute of Soil Science, Chinese Academy of Sciences, Nanjing, 210008, China \\ ${ }^{\mathrm{c}}$ Key Laboratory of Coastal Environmental Processes and Ecological Remediation, Yantai Institute of Coastal Zone Research, Chinese Academy of Sciences, \\ Yantai, 264003, China
}

\section{A R T I C L E I N F O}

\section{Article history:}

Received 29 April 2018

Received in revised form

11 September 2018

Accepted 25 September 2018

Available online 28 September 2018

\section{Keywords:}

Antibiotics

Adsorption

Microplastics

Polystyrene foam

Aging surface

\begin{abstract}
A B S T R A C T
Microplastic polystyrene foam has been found widely in the environment and is readily transported by wind or water. Beached and virgin foams of size $0.45-1 \mathrm{~mm}$ were prepared as sorbents to study oxytetracycline sorption. Enhanced adsorption were found in the beached foams compared to the virgin foams, corresponding to the higher specific surface area, micropore area and the degree of oxidation of the former. The Freundlich $K_{\mathrm{f}}$ value was $894 \pm 84\left(\left(\mathrm{mg} \mathrm{kg}^{-1}\right)\left(\mathrm{mg} \mathrm{L}^{-1}\right)^{1 / \mathrm{n}}\right)$ for oxytetracycline adsorption on the beached foams, approximately twice as high as on the virgin foams. Effects of solution $\mathrm{pH}$ on adsorption to the beached foams were more pronounced to the virgin foams. Maximum adsorption occurred at $\mathrm{pH} 5$ at which electrostatic repulsion between the microplastic surface and the oxytetracycline zwitterion was minimal, indicating that electrostatic interaction may have regulated adsorption. Moreover, H-bonding and multivalent cationic bridging mechanisms may also have affected the adsorption of oxytetracycline to the beached foams as reflected by the ionic effects. Adsorption was promoted more in the presence of humic acid than of fulvic acid, perhaps owing to $\pi$ - $\pi$ conjugation between the humic acid and the microplastic surface which led to enhanced electrostatic attraction for oxytetracycline. This study suggests that weathered polystyrene foams may act as carriers of antibiotics in the environment and their potential risks to ecosystem and human health merit further investigation.
\end{abstract} (c) 2018 Elsevier Ltd. All rights reserved.

\section{Introduction}

Pollution by microplastics limited in size to $<5.00 \mathrm{~mm}$ is recognized as a global threat to marine and coastal environments (Thompson et al., 2004). A total count of $4.85 \times 10^{12}$ pieces of microplastics weighing 35540 tonnes are estimated to be floating on the world's oceans by Eriksen et al. (2014). In particular, polystyrene foams have been found to be widely distributed in freshwater and coastal seawaters and on beaches owing to aquaculture activities (Zhou et al., 2011; Lee et al., 2013; Graca et al., 2014; Zhou et al., 2018). The breakdown of expanded polystyrene (EPS) debris under exposure to UV radiation and the physical effects of wind, currents, waves, and tides may cause the prevalence of

\footnotetext{
This paper has been recommended for acceptance by Maria Cristina Fossi.

* Corresponding author.

E-mail address: hbzhang@zafu.edu.cn (H. Zhang).
}

microplastics in the marine environment (Lee et al., 2013). Owing to their small size and their presence in both pelagic and benthic ecosystems, microplastics have the potential to be ingested by an array of marine biota including zooplankton, mussels, seabirds, and whales (Browne et al., 2008; Cole et al., 2013; Tanaka et al., 2013; Li et al., 2015; Syberg et al., 2015).

Moreover, microplastics are prone to adsorb anthropogenic pollutants from the environment due to their special surface properties (i.e. higher specific surface area, porosity, amorphous structure) formed under long-term environmental weathering and thus contribute to diffuse pollution on coasts and in oceans (Graca et al., 2014; Brenneckea et al., 2016). A global survey of persistent organic pollutants in resin pellets shows that a range of pollutants, including polychlorinated biphenyls (PCBs), DDE and $\mathrm{HCH}$ can be monitored in the resin pellets and their concentrations are related to the local usage of persistent organic pollutants in the areas sampled (Ogata et al., 2009). Several other investigations also indicate the occurrence of organic pollutants (PAHs, PCBs) in 
different types of microplastics, and aged microplastics usually contain higher concentrations of the pollutants (Endo et al., 2005; Frias et al., 2010). Our survey of organophosphorus esters and phthalates in the different beached microplastics revealed that polystyrene foams contained higher concentrations of PAHs and PCBs than did other types of microplastic (Zhang et al., 2018).

Sorption of organic pollutants on microplasitcs varies with their properties and polymer types. The sorption of hydrophobic organic pollutants (e.g. PAHs) on polyethylene pellets is positively correlated with the octanol-water partition coefficients $\left(K_{\mathrm{ow}}\right)$ (Fries and Zarfl, 2012). Similar trends have also been observed in the adsorption of antibiotics on microplastics of different polymer types (Li et al., 2018). On the other hand, polymer types and their properties also determine their sorption of contaminants. Wang et al. (2015) studied the sorption of perfluorooctanesulfonamide (FOSA) on three polymers and found that the equilibrium partition coefficient $\left(K_{\mathrm{d}}\right)$ followed the sequence polyethylene $>$ polypropylene $>$ polyvinyl chloride. Microplastic properties are important in the regulation of sorption. Guo et al. (2012) observed that the crystallinity of sorption domains on the surface of polyethylene had a negative effect on its sorption of compounds such as phenanthrene, naphthalene and 1-naphthol. Surface charge is another critical coefficient influencing sorption. The negative surfaces of some microplastics (e.g. polystyrene particles) show electrostatic repulsion of anions and hence decrease sorption (Wang et al., 2015). However, the surface charge of microplastics may be altered under environmental weathering and thus change their sorption of compounds (Fotopoulou and Karapanagioti, 2015).

Oxytetracycline (OTC) is a broad-spectrum antibiotic in the tetracycline class and is commonly used in veterinary medicine and therefore occurs widely in livestock and poultry production and in aquaculture (Chen et al., 2015a; Zhang et al., 2015). The basic chemical structure of OTC consists of a hydronaphthalene nucleus containing four hexacyclic fused rings, with its molecular weight of $460.4 \mathrm{~g} / \mathrm{mol}$. It is a hydrophilic compound with a low octanol-water partition coefficient $\left(\log K_{\mathrm{ow}}=-1.22\right)$ and high water solubility $(\mathrm{S}=1 \mathrm{~g} / \mathrm{L})$ (Tolls, 2001). Numerous surveys indicate pollution by veterinary antibiotics in surface waters and sediments of the coastal and marine environment (Liang et al., 2013; Zhang et al., 2013; Shi et al., 2014; Chen et al., 2015b; Liu et al., 2016) and some studies indicate that OTC predominates over other antibiotics. Maximum concentrations up to $15163 \mathrm{ng} \mathrm{L}^{-1}$ in seawater (Chen et al., 2015b) and $4695 \mathrm{ng} \mathrm{g}^{-1}$ (Liu et al., 2016) in sediments in the South China Sea and in the Bohai Sea, respectively, have been reported. Aquatic toxicity test indicated that OTC exhibited population growth inhibition on $P$. subcapitata, with $\mathrm{EC}_{50}$ ranging of $0.11-0.25 \mathrm{mg} \mathrm{L}^{-1}$ (Isidori et al., 2005). Moreover, the residue of OTC may induce the prevalence antibiotics resistance genes (ARGs) in the environments and even pose risks to human health (Jiang et al., 2013). In the present study, we hypothesized that OTC and microplasitcs may occur together in coastal and marine environments. In this context, more highly weathered microplastics may have a higher affinity for the sorption of OTC and contribute to the determination of its ultimate environmental fate. Our objective was to examine the mechanisms involved in the enhanced adsorption of OTC on weathered microplastics.

\section{Materials and methods}

\subsection{Materials and reagents}

Analytical grade pure oxytetracycline standard was purchased from Dr. Ehrenstorfer GmbH, Augsburg, Germany. High performance liquid chromatography (HPLC) grade methanol in mobile phase was purchased from Merck Company, Darmstadt, Germany.
Analytical grade humic and fulvic acids were purchased from Sigma-Aldrich Co. Ltd., Poole, UK. All other chemical reagents used in the experiment were analytical grade and were purchased from Sinopharm Chemical Reagent Co., Ltd., Shanghai, China.

\subsection{Preparation of microplastics}

Two microplastic types of same polymer type were used as sorbents. Beached polystyrene foams were prepared using plastic debris collected from the coastal beaches of North China. The weathered external surfaces of the plastic debris were peeled off and retained and were then ground using an analytical mill (IKA Co., Ltd, Staufen, Germany). Virgin foams were prepared using purchased polystyrene foams and complete new plastics blocks were also ground. Both types of ground foam particles were passed through 1.00 - and $0.45-\mathrm{mm}$ sieves sequentially and particles of size range $0.45-1.00 \mathrm{~mm}$ were collected and washed with $\mathrm{n}$-hexane and methanol for $24 \mathrm{~h}$ and dried at room temperature before use in batch experiments.

\subsection{Characterization of microplastics}

The prepared microplastics were characterized by attenuated

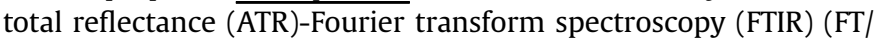
IR-4100 Jasco Inc., Tokyo, Japan), scanning electron photomicrography (SEM) (S-4800 Hitachi, Tokyo, Japan), $\mathrm{N}_{2}$-BET methods using a surface area and porosimetry analyzer (Nova 3200e, Quantachrome Instruments, Boynton Beach, FL) for identification of the component polymers, surface micro-morphology, specific surface area and pore volume of the particles, respectively. The carbon contents of the microplastic particles were analyzed using an elemental analyzer (Vario Micro, Elementar Analysensysteme $\mathrm{GmbH}$, Lagenselbold, Germany). The point of zero charge (PZC) was measured using potentiometric titration (ZDJ-4A, Inesa Instruments, Shanghai, China).

\subsection{Batch experiments}

The batch experiments were conducted in triplicate and included OTC- and microplastic-free controls. Experiments on adsorption kinetics were conducted using $50 \mathrm{mg}$ foam particles and $30 \mathrm{~mL}$ stock solution containing $20 \mathrm{mg} \mathrm{L}^{-1}$ of OTC in $50-\mathrm{mL}$ brown glass centrifuge tubes. The stock solution contained background solutions comprising $0.01 \mathrm{~mol} \mathrm{~L}^{-1} \mathrm{NaCl}$ as electrolyte and $25 \mathrm{mg} \mathrm{L}^{-1} \mathrm{NaN}_{3}$ as biocide. Each centrifuge tube was wrapped with aluminum foil to preventing photodegradation of the chemicals. Three replicates were prepared for each time interval and each treatment, and then all the samples were shaken in the dark at $25 \pm 1{ }^{\circ} \mathrm{C}$ for 14 time intervals within $72 \mathrm{~h}$ in a thermostatic shaker at $150 \mathrm{rpm}$. The stock solution was filtered at each sample interval and the supernatant was reserved for the analysis of OTC concentration.

Sorption isotherm experiments were carried out with a series of initial concentrations of OTC ranging from 2 to $50 \mathrm{mg} \mathrm{L}^{-1}$, and the equilibrium time was set at $54 \mathrm{~h}$ based on previous experiments. Three replicates were prepared for each initial concentration treatment.

Effects of solution $\mathrm{pH}$ and ion strength on the adsorption of OTC to the foam particles were evaluated. The initial solution $\mathrm{pH}$ was adjusted using $\mathrm{NaOH}$ and $\mathrm{HCl}$ solutions, and a wide range of $\mathrm{pH}$ values from 2 to 10 was investigated. Different ions and anions were used to investigate the effects of ion strength. A series of salt concentrations corresponding to the ion intensity gradients of the $\mathrm{CaCl}_{2}, \mathrm{NaCl}$, and $\mathrm{Na}_{2} \mathrm{SO}_{4}$ stock solutions were prepared for the experiments. 
Effects of dissolved organic matter (DOM) on the adsorption of OTC to the beached polystyrene foams were examined using humic acid (HA) and fulvic acids (FA) as the two representative dissolved organic materials. HA and FA solution was prepared by dissolving them in alkaline solution $(\mathrm{pH} \approx 9)$ and diluted to $1000 \mathrm{mg} \mathrm{L}^{-1}$ with $0.01 \mathrm{~mol} \mathrm{~L}^{-1} \mathrm{NaCl}$ as a stock solution. The $\mathrm{pH}$ of the stock solution was adjusted to 6.5 before using in experiment and passed through a Whatman GF/C filter $(0.45 \mu \mathrm{m})$. The dissolved organic carbon (DOC) content in the filtered solution was $480 \mathrm{mg} \mathrm{L}^{-1}$ and $320 \mathrm{mg} \mathrm{L}^{-1}$ for $\mathrm{HA}$ and $\mathrm{FA}$, respectively. A series of sorption isotherm experiments were conducted in the presence of humic or fulvic acid with DOC gradient concentrations (10, 30, 50, $\left.100 \mathrm{mg} \mathrm{L}^{-1}\right)$. The Freundlich coefficients $\left(K_{\mathrm{f}}\right.$ and $\left.1 / \mathrm{n}\right)$ of each sorption isotherm experiment were used to compare the effects of DOM on adsorption.

The loss of compound from the sorption to glass walls was evaluated with microplastic-free controls. The controls were prepared with the same concentrations and shaken for same time periods during the above experiments.

\subsection{Instrumental analysis}

Aqueous OTC concentration was quantified with a Waters Acquity Ultra Performance Liquid Chromatography (UPLC) system (Waters Corp., Milford, MA) with a photodiode array (PDA) detector. Separation of the compound was performed on a Waters $\mathrm{BEH}$ C18 column $(2.1 \mathrm{~mm} \times 50 \mathrm{~mm}, 1.7 \mu \mathrm{m}$ in diameter $)$ at a constant temperature of $35^{\circ} \mathrm{C}$. The sample was isocratically eluted with a mobile phase of $0.126 \%$ oxalic acid $(80 \%)$, acetonitrile (10\%) and methanol $(10 \%)$ at a flow rate of $0.3 \mathrm{~mL} \mathrm{~min}^{-1}$. The detector wavelength was set to $355 \mathrm{~nm}$.

\subsection{Adsorption kinetic and isotherm models}

The experimental data obtained for the adsorption kinetic studies were fitted to intraparticle diffusion and film diffusion models as suggested by Martins et al. (2015). Adsorption isotherm data were fitted to linear model, the Langmuir model and the Freundlich model as described by Teuten et al. (2007). All the models used in studies are listed in Table 1.

\section{Results and discussion}

\subsection{Characteristics of the beached polystyrene foams}

The beached foams were very different from the virgin foams based on external surface color (Fig. 1) and other surface properties (Table 2). A darker color was visualized in the beached compared with the virgin foams. In contrast to the smooth and uniform surfaces of the virgin particles, surfaces of the beached foams were rough and uneven as shown in the SEM images. Similar results have been observed in other investigations of weathered microplastic particles (Fotopoulou and Karapanagioti, 2015). The rough surfaces of the beached particles generated a higher specific surface area and micropore area than the virgin foam particles as indicated in Table 2 . However, the pore volume of the beached particles was smaller than that of the virgin foams. This may be attributed to the reshaping of the polymer surface under erosion (Fotopoulou and Karapanagioti, 2015). The point of zero charge (PZC) increased slightly from 4.68 on the virgin particles to 4.96 on the beached particles. The surfaces of the foams are therefore generally negatively charged in marine ( $\mathrm{pH} \sim 8.1$ ) or terrestrial ( $\mathrm{pH} \mathrm{6-7)}$ waters.

Surface oxidation of the beached microplastics was observed as indicated in the FT-IR spectra (Fig. S1). A wide peak showing ester (C-O) stretch can be observed in the shadow shape area of Fig. 2. The band intensity was higher in the beached sample than the virgin sample. Moreover, the ester carbonyl bond index and ketone carbonyl bond index were calculated to compare the extent of oxidation between these two samples. As shown in Table 1, the ester carbonyl bond index was higher in the beached samples but the ketone carbonyl bond index was similar in both samples. This indicates that the beached polystyrene foams were subjected to greater surface oxidation than the virgin foams and had a higher hydrophilicity due to the increase in oxidized functional groups (Restrepo-Florez et al., 2014).

\subsection{Adsorption kinetics}

Adsorption kinetics typically involves four consecutive steps (Ho et al., 2000): (1) bulk transport, (2) film transport, (3) intra-particle transport and (4) adsorption on the adsorbent. In order to understand the rate controlling factors of OTC adsorption onto the microplastics, the intra-particle diffusion and film diffusion models were used in this study. The intra-particle diffusion model proposed by Weber and Morris (1962) assumes that the adsorption mechanism occurs through the diffusion of adsorbates into the pores of adsorbent material. The plots obtained for $q_{\mathrm{t}}$ versus $t^{1 / 2}$ are shown in Fig. 2 and the values of $K_{\mathrm{id}}, C_{\mathrm{i}}$ and $r^{2}$ are presented in Table 3. As shown in Fig. 2(1), the plot is distributed in three linear segments indication of three different adsorption stages of OTC in the virgin PS foam particles. While the adsorption of OTC in the beached PS foam particles can be divided into two stages only as shown in Fig. 2(2). However, the $K_{\text {id }}$ values of the first stage are lower than the second stage for both particles (Table 3), which demonstrated that the adsorption rate is higher at the second stage

Table 1

Kinetic and isotherm models used in the studies.

\begin{tabular}{llr}
\hline Names & Equations & References \\
\hline $\begin{array}{l}\text { Kinetic models } \\
\text { Intraparticle diffusion }\end{array}$ & $q_{t}=k_{i d} \times t^{1 / 2}+C_{i}$ & Weber and Morris, 1962 \\
$\quad$ Film diffusion & $B_{t}=-\ln \left(1-\frac{q_{t}}{q_{e}}\right)-0.4977$ & Martins et al., 2015 \\
Isotherm models & $q_{e}=k_{d} \times C_{e}$ & Teuten et al., 2007 \\
$\quad$ Liner & $q_{e}=\frac{Q_{\max } \times k_{L} \times C_{e}}{1+k_{1} \times C_{e}}$ & Teuten et al., 2007 \\
$\quad$ Langmuir & $q_{e}=K_{f} \times C_{e}^{\frac{1}{n}}$ & Teuten et al., 2007 \\
Freundlich & & \\
\end{tabular}

$q_{\mathrm{e}}=$ adsorbed amount at equilibrium, $q_{\mathrm{t}}=$ adsorbed amount at time $t, k_{\mathrm{id}}$ and $C_{\mathrm{i}}=$ intraparticle diffusion constants, $B_{\mathrm{t}}=$ Boyd constant, $k_{\mathrm{d}}=$ partition coefficient between sorbent and solution at equilibrium, $C_{\mathrm{e}}=$ OTC concentration in the supernatant at equilibrium. $Q_{\max }=$ maximum adsorption capacity, $k_{\mathrm{L}}=$ Langmuir constant, $K_{\mathrm{f}}$ and $1 / n=$ Freundlich constants.

The film diffusion model was simplified from the Boyd model, which is given as follows: $\frac{q_{t}}{q_{e}}=1-\frac{6}{\pi^{2}} \sum_{m=1}^{\infty} \frac{1}{m^{2}} \exp \left(-m^{2} B_{t}\right)$. 

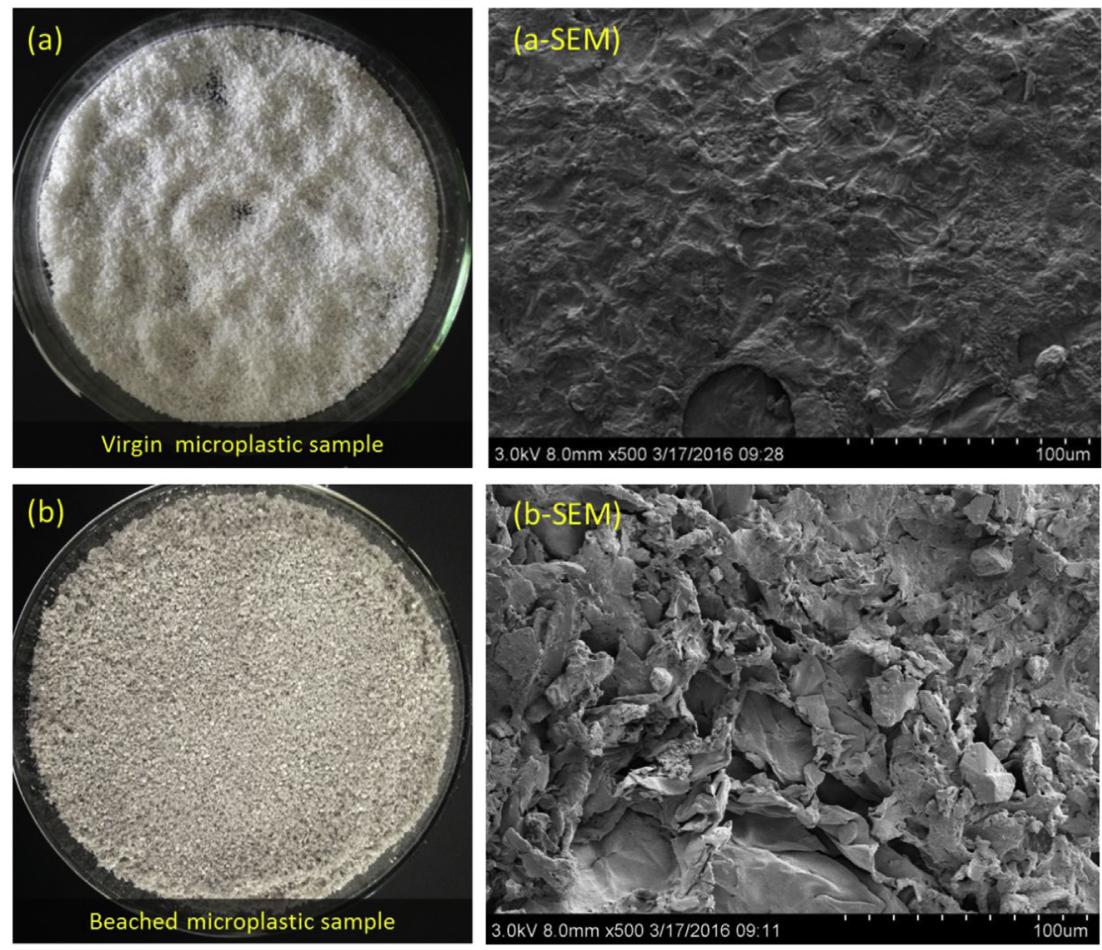

Fig. 1. Photomicrographs showing the polystyrene foam particles (a and b) and their microscopic surface morphologies (a-SEM and b-SEM).

Table 2

Characteristics of the virgin and beached polystyrene samples used for the experiments.

\begin{tabular}{lll}
\hline Property & Virgin polystyrene foams & Beached polystyrene foams \\
\hline Particle size $(\mathrm{mm})$ & $0.45-1$ & $0.45-1$ \\
Carbon content $\%$ & $90.6 \pm 0.8$ & $90.4 \pm 1.2$ \\
$\mathrm{PZC}$ & $4.7 \pm 0.2$ & $5.0 \pm 0.2$ \\
$\mathrm{SSA}\left(\mathrm{m}^{2} \mathrm{~g}^{-1}\right)$ & $2.03 \pm 0.04$ & $7.91 \pm 0.16$ \\
Micropore $(<2 \mathrm{~nm})$ area $\left(\mathrm{m}^{2} \mathrm{~g}^{-1}\right)$ & $\mathrm{n} . \mathrm{d}$ & $0.50 \pm 0.02$ \\
Average pore diameter $(\mathrm{nm})$ & $39.3 \pm 0.5$ & $5.1 \pm 0.2$ \\
Pore volume $\left(\mathrm{cm}^{3} \mathrm{~g}^{-1}\right)$ & $0.02 \pm 0.005$ & $0.01 \pm 0.005$ \\
Ester carbonyl bond index & 0.55 & 0.73 \\
Ketone carbonyl bond index & 0.30 & 0.33 \\
\hline
\end{tabular}

PZC, the point of zero charge; SSA, the specific surface area measured using the BET- $\mathrm{N}_{2}$ method; n.d. indicated not detected.
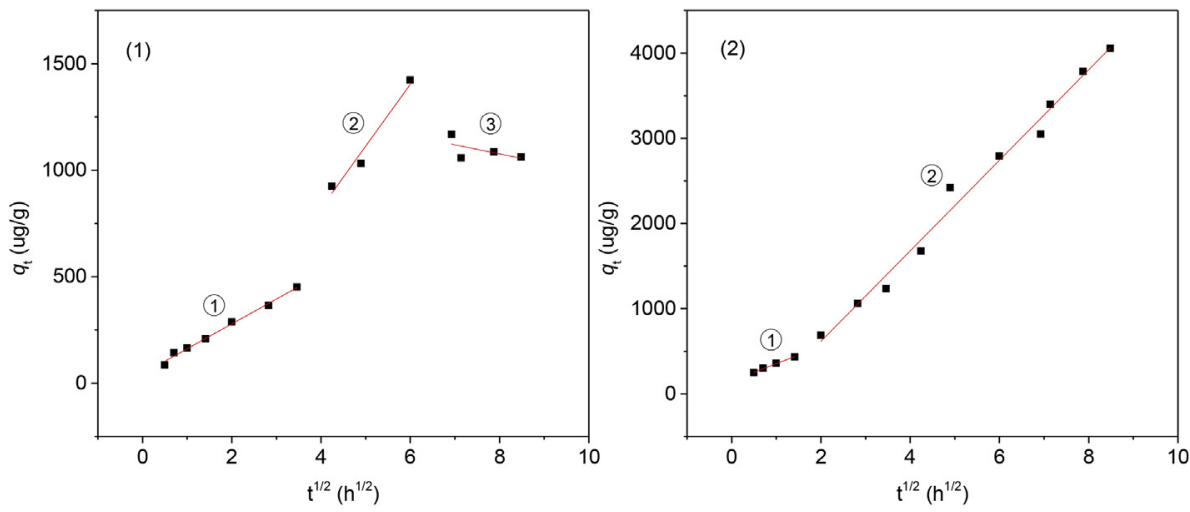

Fig. 2. Intraparticle diffusion plots for adsorption of OTC in (1) virgin sample and (2) beached sample.

than at the first stage. The higher $r^{2}$ values of the linear segments for both particles indicated that the intra-particle diffusion is the rate-limiting step. Furthermore, the first and second stages pass away from the origin, implying that the rate-limiting step of adsorption process was not governed only by intra-particle diffusion (Martins et al., 2015).

The Boyd plot (Fig. 3) was obtained by plotting $B_{\mathrm{t}}$ versus time and is useful to identify if the rate-limiting step is intra-particle 
Table 3

The coefficients of intraparticle diffusion for oxytetracycline adsorption in the polystyrene foam particles.

\begin{tabular}{llll}
\hline Microplastics & \multicolumn{2}{l}{ Intraparticle diffusion cofficients } \\
\cline { 2 - 4 } & $K_{\mathrm{id}, \mu \mathrm{g} \mathrm{g}^{-1} \mathrm{~h}^{-1 / 2}}$ & $C_{\mathrm{i}, \mu \mathrm{g} \mathrm{g}^{-1}}$ & $r^{2}$ \\
\hline Virgin polystyrene foams & & & \\
Segment (1) & 117 & 45.2 & 0.99 \\
Segment (2) & 291 & -342 & 0.94 \\
Segment (3) & -42.5 & 1420 & 0.014 \\
Beached polystyrene foams & & \\
Segment (1) & 202 & 154 & 0.99 \\
Segment (2) & 531 & -446 & 0.98 \\
\hline
\end{tabular}

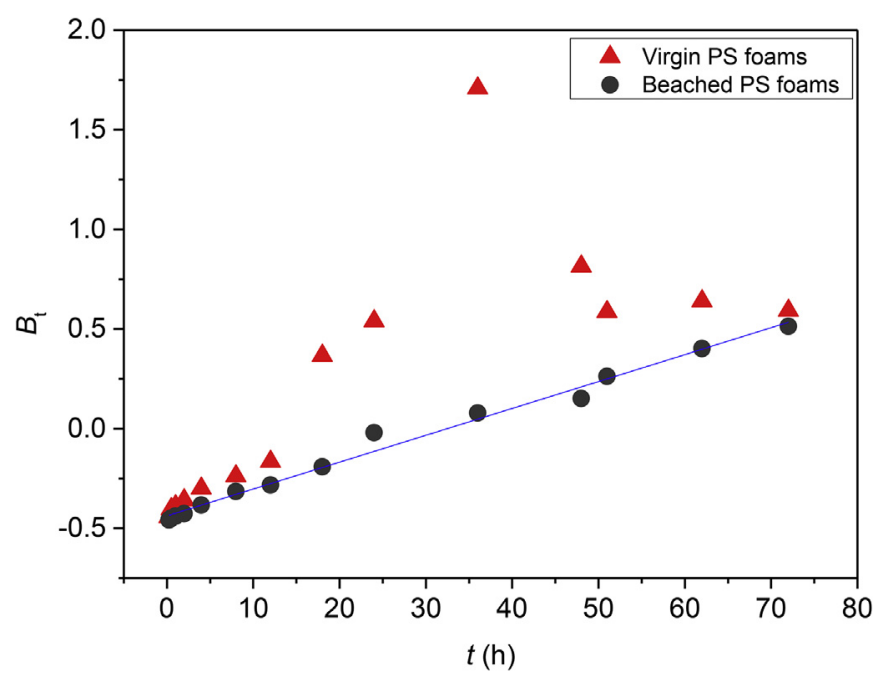

Fig. 3. Plot of $B_{\mathrm{t}}$ versus time (h) (Boyd's plot) for OTC adsorption in the microplastics.

diffusion or film diffusion (Martins et al., 2015). When the data points are fitting linear and pass through the origin there is evidence that intra-particle diffusion is the rate-limiting step of adsorption process. Otherwise film diffusion is involved in the adsorption process (Hu et al., 2011). As shown in Fig. 3, the plot presents linearity for the OTC adsorption in the beached PS foam particles but passes away from the origin, which suggested both intra-particle diffusion and film diffusion are involved in the adsorption process. While the plot presents neither linearity nor through origin for the virgin PS foam particles, attesting the film diffusion controlled mechanism in the adsorption process. The difference of adsorption mechanisms between the virgin sample and beached sample is corresponding to the different porosity of the two adsorbents as shown in Fig. 1 and Table 2.

\subsection{Adsorption isotherms}

The sorption isotherms were described with linear, Langmuir and the Freudlich models as shown in Table 4. The Freudlich model was the best fitting of the three models for adsorption based on adjusted $R^{2}$ values, and the linear and Langmuir models also fitted significantly $(p<0.01)$. The Freundlich model is used to describe nonlinear sorption, where $K_{\mathrm{f}}$ and $1 / \mathrm{n}$ are the sorption affinity coefficient and linearity index, respectively (Tolls, 2001). The $1 / \mathrm{n}$ values indicate that the oxytetracyline was adsorbed nonlinearly on both polystyrene foam types as reflected by greater departure of the Freundlich $1 / \mathrm{n}$ value from 1 (Table 4 ). In general, a more sorption nonlinearity indicates a more heterogeneous distribution of sorption sites, likely resulting from specific sorbate-sorbent interactions (Sun et al., 2010). The nonlinearity also suggested the presence of pore-filling mechanisms involved in the adsorption process. Ahn et al. (2005) found that the nonlinear adsorption of phenanthrene and pyrene in activated carbon and coke was significantly related to the filling of micro and mesopore space by the compounds at their solubility limits. A higher $K_{\mathrm{f}}$ value of the beached foams suggests that the weathered surfaces had a higher sorption affinity for the oxytetracycline than the virgin surfaces. This is correlated with the higher micropore area of the beached foams than the virgin foams as indicated in Table 2. The different affinity can also be described using the solidwater partition coefficient $\left(K_{\mathrm{d}}\right)$. Tolls (2001) summarized $K_{\mathrm{d}}$ values for oxytetracyline adsorption in different soils and sediments which ranged from 0.3 to $1030 \mathrm{~L} \mathrm{~kg}^{-1}$. The $K_{\mathrm{d}}$ value of the beached foams in the current study falls within this range and is comparable to the value derived from an experiment with loamy sandy soil or marine and freshwater sediments. This implies that the beached polystyrene foams may have a similar affinity for oxytetracycline with these environment matrixes. While the $K_{\mathrm{d}}$ value of the virgin foams is comparable to the results of Sun et al. (2010) who performed a batch sorption experiment with pure polystyrene and tetracycline.

\subsection{Effect of $p H$ on sorption}

Oxytetracycline has three $\mathrm{pk}_{\mathrm{a}}$ values (3.27, 7.32 and 9.11) (Tolls, 2001) and its sorption on the foams depends strongly on the solution $\mathrm{pH}$. As shown in Fig. 4(1), oxytetracycline was mainly in cationic form at $\mathrm{pH}<3.27$, predominated by a zwitterion at $\mathrm{pH}$ values $3.27-7.32$ and dominated by anions $\left(\right.$ OTC $^{-}$and OTC $^{2-}$ ) when $\mathrm{pH}>7.32$. Changes in oxytetracycline adsorption on the foams with changing $\mathrm{pH}$ are more prominent for the beached samples than the virgin samples (Fig. 4(2)). The maximum adsorption for the beached samples occurred at approximately $\mathrm{pH} 5$, corresponding to the highest proportion (97.7\%) of oxytetracycline zwitterion in the solution. The surface charge of the beached sample approached the point of zero charge (PZC 4.96) at this $\mathrm{pH}$ value and had the lowest electrostatic repulsion for oxytetracycline. At $\mathrm{pH}<5.0$ or $>5.0$, the electrostatic repulsion was higher due to the similarly charged sorbent and sorbate. Several studies have reported the $\mathrm{pH}$ dependence of adsorption of antibiotics, including adsorption to clay minerals (Essington et al., 2010), goethite (Zhao et al., 2011) and to organic matter (Sun et al., 2010). In addition, the weathered surface of polystyrene foams contain more carboxyl and ester carbonyl groups as indicated in Table 2 and Fig. S1 and this might facilitate oxytetracycline adsorption through H-bonding mechanisms other

Table 4

The coefficients of adsorption isotherms for oxytetracycline to the polystyrene foams.

\begin{tabular}{|c|c|c|c|c|c|c|c|c|c|}
\hline \multirow[t]{2}{*}{ Microplastics } & \multicolumn{2}{|l|}{ Linear model } & \multirow[t]{2}{*}{$r^{2}$} & \multicolumn{2}{|c|}{ Langmuir model } & \multirow[t]{2}{*}{$r^{2}$} & \multicolumn{3}{|l|}{ Freundlich model } \\
\hline & $\mathrm{K}_{\mathrm{d}}\left(\mathrm{mL} \mathrm{g}^{-1}\right)$ & $\mathrm{K}_{\mathrm{oc}}\left(\mathrm{mL} \mathrm{g}^{-1}\right)$ & & $\mathrm{K}_{\mathrm{L}}\left(\mathrm{L} \mu \mathrm{g}^{-1}\right)$ & $\mathrm{Q}_{\max }\left(\mu \mathrm{g} \mathrm{g}^{-1}\right)$ & & $\mathrm{K}_{\mathrm{f}}\left(\left(\mathrm{mg} \mathrm{kg}^{-1}\right)\left(\mathrm{mg} \mathrm{L}^{-1}\right) 1 / \mathrm{n}\right)$ & $1 / \mathrm{n}$ & $r^{2}$ \\
\hline Virgin polystyrene foams & $41.7 \pm 5.0$ & $46.0 \pm 5.5$ & 0.87 & $0.17 \pm 0.06$ & $1520 \pm 120$ & 0.86 & $425 \pm 46$ & $0.32 \pm 0.03$ & 0.94 \\
\hline Beached polystyrene foams & $428.4 \pm 15.2$ & $474.0 \pm 16.8$ & 0.99 & $0.02 \pm 0.01$ & $27500 \pm 5120$ & 0.99 & $894 \pm 84$ & $0.75 \pm 0.03$ & 0.99 \\
\hline
\end{tabular}

$\mathrm{K}_{\mathrm{oc}}$ was calculated using the equation $\mathrm{K}_{\mathrm{oc}}=\mathrm{K}_{\mathrm{d}} / f_{\mathrm{oc}}$, where $f_{\mathrm{oc}}$ is the organic carbon fraction of the samples. 

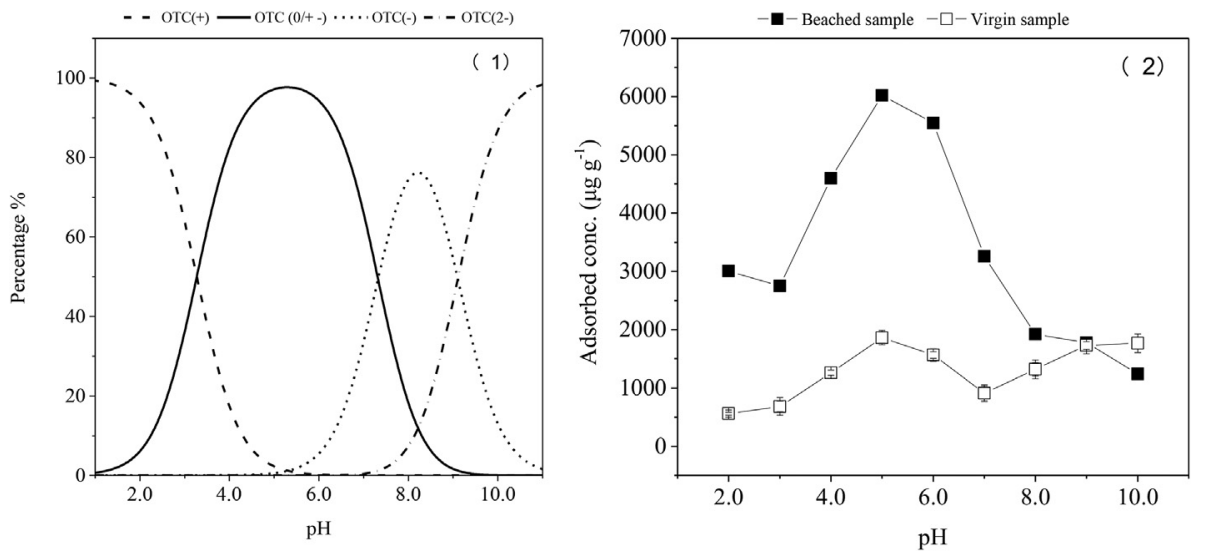

Fig. 4. (1) Changes in oxytetracycline speciation with $\mathrm{pH}$ and (2) the effect of solution $\mathrm{pH}$ on the adsorption of oxytetracycline to the microplastics.

than electrostatic attraction (Tolls, 2001). The virgin plastics contained no proton-complexing group as used in the study of Sun et al. (2010) and were essentially unaffected by pH.

\subsection{Effect of ionic strength on sorption}

The effect of ionic strength of $\mathrm{NaCl}, \mathrm{CaCl}_{2}$ or $\mathrm{Na}_{2} \mathrm{SO}_{4}$ on oxytetracycline sorption to polystyrene foams is presented in Fig. 5. Clearly, oxytetracycline sorption to both types of foam decreased with increasing ionic intensity. This may be attributed to ionic competition, in particular the higher $\mathrm{Ca}^{2+}$ and $\mathrm{Na}^{+}$may strongly compete for cationic exchange sites (i.e. carboxyl groups) on the microplastic surfaces (Li et al., 2018). Oxytetracycline sorption to the microplastics was stronger in the presence of $\mathrm{CaCl}_{2}$ than of $\mathrm{NaCl}$ or $\mathrm{Na}_{2} \mathrm{SO}_{4}$ at the range of ionic intensity tested. This suggests that oxytetracycline sorption to the foams may be facilitated by multivalent cations such as $\mathrm{Ca}^{2+}$ through formation of ternary complexes between the cations and oxytetracycline and the surface functional groups (MacKay and Canterbury, 2005). However, a difference in ionic effects on the sorption can be observed between the beached samples and virgin samples. In particular, the suppressive effect on oxytetracycline sorption by $\mathrm{Na}^{+}$was more pronounced in virgin samples than in beached samples (Fig. 5). This implies that oxytetracycline sorption to the virgin polystyrene was mainly dominated by cationic exchange mechanisms while its sorption to the beached microplastic particles was dominated by other alternative mechanisms (H-bonding or hydrophobic interaction) other than cationic exchange (Tolls, 2001; Ocampo-Perez et al., 2015).

\subsection{Effect of dissolved organic matter on sorption}

Table 5 summarizes the Freundlich coefficients for oxytetracycline sorption to the beached foams in the presence of humic or fulvic acid with gradient concentrations. The $K_{\mathrm{f}}$ value increases significantly from $2424\left(\mathrm{mg} \mathrm{kg}^{-1}\right)\left(\mathrm{mg} \mathrm{L}^{-1}\right)^{1 / \mathrm{n}}$ to $5343\left(\mathrm{mg} \mathrm{kg}^{-1}\right)$

Table 5

Comparison of the Freundlich coefficients of oxytetracylcine adsorption to the beached polystyrene foams between the presence of different concentrations of humic acid and fulvic acid.

\begin{tabular}{lllll}
\hline Freundlich coefficients & \multicolumn{4}{c}{ Organic matter concentration $\left(\mathrm{mg} \mathrm{L}^{-1}\right)$} \\
\cline { 2 - 5 } & 10 & 30 & 50 & 100 \\
\hline Humic acid & & & & \\
$K_{f}\left(\left(\mathrm{mg} \mathrm{kg}^{-1}\right)\left(\mathrm{mg} \mathrm{L}^{-1}\right)^{1 / n}\right)$ & 2420 & 3640 & 5340 & 3940 \\
$1 / \mathrm{n}$ & 0.29 & 0.24 & 0.10 & 0.23 \\
$r^{2}$ & 0.95 & 0.98 & 0.96 & 0.97 \\
Fulvic acid & & & & \\
$K_{f}\left(\left(\mathrm{mg} \mathrm{kg}^{-1}\right)\left(\mathrm{mg} \mathrm{L}^{-1}\right)^{1 / n}\right)$ & 1580 & 1450 & 1670 & 1980 \\
$1 / \mathrm{n}$ & 0.43 & 0.48 & 0.47 & 0.44 \\
$r^{2}$ & 0.97 & 0.97 & 0.96 & 0.97 \\
\hline
\end{tabular}

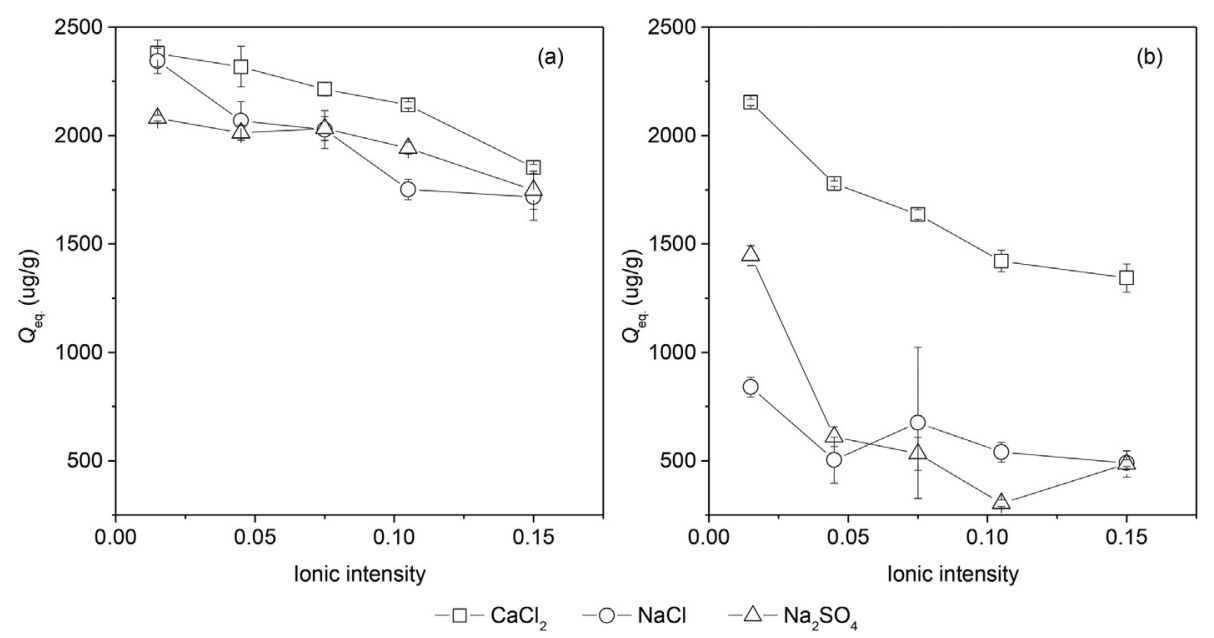

Fig. 5. Influence of ions and their intensities on the adsorption of oxytetracycline to (1) the beached microplastic sample and (2) the virgin sample. 
$\left(\mathrm{mg} \mathrm{L}^{-1}\right)^{1 / \mathrm{n}}$ with increasing humic acid concentration from 10 to $50 \mathrm{mg} \mathrm{L}^{-1}$ and declines to $3939\left(\mathrm{mg} \mathrm{kg}^{-1}\right)\left(\mathrm{mg} \mathrm{L}^{-1}\right)^{1 / \mathrm{n}}$ at a humic acid concentration of $100 \mathrm{mg} \mathrm{L}^{-1}$. In contrast, the $K_{\mathrm{f}}$ value changes slightly from $1578\left(\mathrm{mg} \mathrm{kg}^{-1}\right)\left(\mathrm{mg} \mathrm{L}^{-1}\right)^{1 / \mathrm{n}}$ to $1982\left(\mathrm{mg} \mathrm{kg}^{-1}\right)(\mathrm{mg}$ $\left.\mathrm{L}^{-1}\right)^{1 / \mathrm{n}}$ when the fulvic acid concentration increases from 10 to $100 \mathrm{mg} \mathrm{L}^{-1}$.

A significant promotion of oxytetracycline sorption to the beached foams by humic acid may be attributed to the complex of humic acid acting as a bridge with both the beached foam surfaces and oxytetracycline molecules (Sun et al., 2010; Zhao et al., 2011; Zhao et al., 2012; Chen et al., 2018). The complexation mechanism of tetracycline antibiotics with humic acid has been proposed in numerous studies to be formed by cationic or zwitterionic tetracycline species with the deprotonated sites on humic acid via $\mathrm{H}-$ bonding and cation exchange (Sun et al., 2010; Zhao et al., 2012). However, such a complexation may decrease the adsorption of the antibiotics by microplastics as reported by Wu et al. (2016) and Seidensticker et al. (2017) who applied polyethylene (PE) as an adsorbent. Their studies reported that humic acid has negligible affiliation to PE particles likely due to the hydrophilic properties of the humic acid. However, the PS microplastics are much different to the PE particles in structure. The PS foam contains substantial benzene rings and a large portion of condensed domains which increase nonlinear sorption for humic acid (Guo et al., 2012). A recent study shows that polystyrene microplastics can be entrapped in the DOM polymers by interaction with the aromatic structure of DOM via $\pi-\pi$ conjugation, which results in a highly conjugated co-polymer with increased electron density (Chen et al., 2018). This conjugated co-polymer may increase the electrostatic attraction for cationic or zwitterionic oxytetracycline. Furthermore, increase of ester functional groups and specific surface area of the beached foams as a result of high weathering (Table 1) may enhance the adsorption of humic acid with hydrophilic properties. In contrast to humic acid, fulvic acid has a lower molecular weight and its $\mathrm{H}: \mathrm{C}$ ratio $>1$ indicates less aromatic character (i.e., fewer benzene rings in the structure) (Chefetz et al., 1998). Hence, this molecular structure had a relatively small impact on the affinity of fulvic acid for polystyrene foams through $\pi-\pi$ conjugation. This may explain the difference in effects between humic and fulvic acids on the sorption of oxytetracycline to the beached polystyrene foams.

\subsection{Environmental implications}

Weathered polystyrene foam particles are ubiquitous in the environment and are characterized of small size and readily transport by wind or water flow (Lee et al., 2013; Zhou et al., 2018). Graca et al. (2014) report that polystyrene foam debris can accumulate larger amounts of mercury than virgin foams, soils or sand samples. The present study further demonstrates that weathered polystyrene foam microplastics also have an enhanced affinity for oxytetracycline which has been detected widely in soils, waters and sediments (Liang et al., 2013; Liu et al., 2016), and hence change the environmental fate and ecotoxicology of antibiotics.

Moreover, oxytetracycline sorption to weathered polystyrene foams clearly changed with changing $\mathrm{pH}$, ionic strength and humic acid concentration. This implies that the sorption affinity may change with changing environmental conditions. Under normal circumstances, the concentration of tetracycline antibiotics is higher in estuaries than in the ocean as we reported in the Bohai Sea (Liu et al., 2016). Estuarine water usually has a lower $\mathrm{pH}$ and ionic strength than seawater. In this context, the role of weathered PS foams as a carrier of antibiotics derived from contaminated estuarine water was non-negligible and they may produce an alternative pathway for antibiotic inputs from inland water to coastal marine (Li et al., 2018). Hence, contamination by antibiotics in the presence of microplastics in the coastal ecosystem merits further detailed investigation.

\section{Acknowledgments}

This research was funded by the National Natural Science Foundation of China (41771351), Zhejiang Agriculture and Forestry University Research Funding (2017FR021) and the Key Project of the Chinese Academy of Sciences (QYZDJ-SSW-DQC05).

\section{Appendix A. Supplementary data}

Supplementary data to this article can be found online at https://doi.org/10.1016/j.envpol.2018.09.122.

\section{References}

Ahn, S., Werner, D., Karapanagioti, H.K., McGlothlin, D.R., Zare, R.N., Luthy, R.G. 2005. Phenanthrene and pyrene sorption and intraparticle diffusion in polyoxymethylene, coke, and activated carbon. Environ. Sci. Technol. 39 (17), 6516-6526.

Brenneckea, D., Duarte, B., Paiva, F., Caçador, I., Canning-Clode, J., 2016. Microplastics as vector for heavy metal contamination from the marine environment. Estuar. Coast Shelf Sci. in press.

Browne, M.A., Dissanayake, A., Galloway, T.S., Lowe, D.M., Thompson, R.C., 2008. Ingested microscopic plastic translocates to the circulatory system of the mussel, Mytilus edulis (L.). Environ. Sci. Technol. 42, 5026-5031.

Chefetz, B., Chen, Y., Hadar, Y., Hatcher, P.G., 1998. Characterization of dissolved organic matter extracted from composted municipal solid waste. Soil Sci. Soc. Am. J. 62, 326-332.

Chen, H., Liu, S., Xu, X.R., Liu, S.S., Zhou, G.J., Sun, K.Y., Zhao, J.L., Ying, G.G., 2015a Antibiotics in typical marine aquaculture farms surrounding Hailing Island South China: occurrence, bioaccumulation and human dietary exposure. Mar. Pollut. Bull. 90, 181-187.

Chen, H., Liu, S., Xu, X.R., Zhou, G.J., Liu, S.S., Yue, W.Z., Sun, K.F., Ying, G.G., 2015b. Antibiotics in the coastal environment of the Hailing Bay region, South China Sea: spatial distribution, source analysis and ecological risks. Mar. Pollut. Bull. 95, 365-373.

Chen, W., Ouyang, Z.Y., Qian, C., Yu, H.Q., 2018. Induced structural changes of humic acid by exposure of polystyrene microplastics: a spectroscopic insight. Environ. Pollut. 233, 1-7.

Cole, M., Lindeque, P., Fileman, E., Halsband, C., Goodhead, R., Moger, J., Galloway, T.S., 2013. Microplastic ingestion by zooplankton. Environ. Sci. Technol. 47, 6646-6655.

Endo, S., Takizawa, R., Okuda, K., Takada, H., Chiba, K., Kanehiro, H., Ogi, H., Yamashita, R., Date, T., 2005. Concentration of polychlorinated biphenyls (PCBs) in beached resin pellets: variability among individual particles and regional differences. Mar. Pollut. Bull. 50, 1103-1114.

Eriksen, M., Lebreton, L.C.M., Carson, H.S., Thiel, M., Moore, C.J., Borerro, J.C., Galgani, F., Ryan, P.G., Reisser, J., 2014. Plastic pollution in the world's oceans: more than 5 trillion plastic pieces weighing over 250,000 tons afloat at sea. PloS One 9.

Essington, M.E., Lee, J., Seo, Y., 2010. Adsorption of antibiotics by montmorillonite and kaolinite. Soil Sci. Soc. Am. J. 74, 1577-1588.

Fotopoulou, K.N., Karapanagioti, H.K., 2015. Surface properties of beached plastics. Environ. Sci. Pollut. Res. Int. 22, 11022-11032.

Frias, J.P., Sobral, P., Ferreira, A.M., 2010. Organic pollutants in microplastics from two beaches of the Portuguese coast. Mar. Pollut. Bull. 60, 1988-1992.

Fries, E., Zarfl, C., 2012. Sorption of polycyclic aromatic hydrocarbons (PAHs) to low and high density polyethylene (PE). Environ. Sci. Pollut. Res. 19, 1296-1304.

Graca, B., Beldowska, M., Wrzesien, P., Zgrundo, A., 2014. Styrofoam debris as a potential Carrier of mercury within ecosystems. Environ. Sci. Pollut. Res. Int. 21, 2263-2271.

Guo, X.Y., Wang, X.L., Zhou, X.Z., Kong, X.Z., Tao, S., Xing, B.S., 2012. Sorption of four hydrophobic organic compounds by three chemically distinct polymers: role of chemical and physical composition. Environ. Sci. Technol. 46, 7252-7259.

Ho, Y.S., Ng, J.C.Y., McKay, G., 2000. Kinetics of polltant sorption by biosorbents: review. Separ. Purif. Technol. 29 (2), 189-232.

Hu, X.-j., Wang, J.-S., Liu, Y.-g., Li, X., Zeng, G.-m., Bao, Z.-l., Zeng, X.-X., Chen, A.-W., Long, F., 2011. Adsorption of chromium (VI) by ethylenediamine-modified crosslinked magnetic chitosan resin: isotherms, kinetics and thermodynamics. J. Hazard Mater. 185, 306-314.

Isidori, M., Lavorgna, M., Nardelli, A., Pascarella, L., Parrella, A., 2005. Toxic and genotoxic evaluation of six antibiotics on non-target organisms. Sci. Total Environ. 346, 87-98.

Jiang, L., Hu, X.L., Xu, T., Zhang, H.C., Sheng, D., Yin, D.Q., 2013. Prevalence of antibiotic resistance genes and their relationship with antibiotics in the Huangpu River and the drinking water sources, Shanghai, China. Sci. Total Environ. 458, 
$267-272$.

Lee, J., Hong S., Song, Y.K., Hong, S.H., Jang Y.C. Jang, M., Heo, N.W., Han, G.M., Lee, M.J., Kang, D., Shim, W.J., 2013. Relationships among the abundances of plastic debris in different size classes on beaches in South Korea. Mar. Pollut. Bull. 77, 349-354.

Li, J., Zhang, K., Zhang, H., 2018. Adsorption of antibiotics on microplastics. Environ. Pollut. 237, 460-467.

Li, J.N., Yang, D.Q., Li, L., Jabeen, K., Shi, H.H., 2015. Microplastics in commercial bivalves from China. Environ. Pollut. 207, 190-195.

Liang, X.M., Chen, B.W., Nie, X.P., Shi, Z., Huang, X.P., Li, X.D., 2013. The distribution and partitioning of common antibiotics in water and sediment of the Pearl River Estuary, South China. Chemosphere 92, 1410-1416.

Liu, X.H., Zhang, H.B., Li, L.Z, Fu, C.C., Tu, C, Huang YJ., Wu, L.H., Tang J.H., Luo, Y.M. Christie, P., 2016. Levels, distributions and sources of veterinary antibiotics in the sediments of the Bohai Sea in China and surrounding estuaries. Mar. Pollut. Bull. 109, 597-602.

MacKay, A.A., Canterbury, B., 2005. Oxytetracycline sorption to organic matter by metal-bridging. J. Environ. Qual. 34, 1964-1971.

Martins, A.C., Pezoti, O., Cazetta, A.L., Bedin, K.C., Yamazaki, D.A.S., Bandoch, G.F.G., Asefa, T. Visentainer, J.V., Almeida, V.C., 2015. Removal of tetracycline by $\mathrm{NaOH}-$ activated carbon produced from macadamia nut shells: kinetic and equilibrium studies. Chem. Eng. J. 260, 291-299.

Ocampo-Perez, R, Leyua-Ramos, R. Rivera-Utrilla, J., Flores-Cano, J.V., Sanchez Polo, M., 2015. Modeling adsorption rate of tetracyclines on activated carbons from aqueous phase. Chem. Eng. Res. Des. 104, 579-588.

Ogata, Y., Takada, H., Mizukawa, K., Hirai, H., Iwasa, S., Endo, S., Mato, Y., Saha, M. Okuda, K., Nakashima, A., Murakami, M., Zurcher, N., Booyatumanondo, R., Zakaria, M.P., Dung, L.Q., Gordon, M., Miguez, C., Suzuki, S., Moore, C., Karapanagioti, H.K., Weerts, S., McClurg, T., Burres, E., Smith, W., Van Velkenburg, M., Lang, J.S., Lang, R.C., Laursen, D., Danner, B., Stewardson, N., Thompson, R.C., 2009. International pellet watch: global monitoring of persistent organic pollutants (POPs) in coastal waters. 1. Initial phase data on PCBs, DDTs, and HCHs. Mar. Pollut. Bull. 58, 1437-1446.

Restrepo-Florez, J.M., Bassi, A., Thompson, M.R., 2014. Microbial degradation and deterioration of polyethylene: a review. Int. Biodeterior. Biodegrad. 88, 83-90.

Seidensticker, S., Zarfl, C., Cirpka, O.A., Fellenberg, G., Grathwohl, P., 2017. Shift in mass transfer of wastewater contaminants from microplastics in the presence of dissolved substances. Environ. Sci. Technol. 51, 12254-12263.

Shi, H., Yang, Y., Liu, M., Yan, C.X., Yue, H.Y., Zhou, J.L., 2014. Occurrence and distribution of antibiotics in the surface sediments of the Yangtze Estuary and nearby coastal areas. Mar. Pollut. Bull. 83, 317-323.

Sun, H.Y., Shi, X., Mao, J.D., Zhu, D.Q., 2010. Tetracycline sorption to coal and soi humic acids: an examination of humic structural heterogeneity. Environ. Toxicol. Chem. 29, 1934-1942.

Syberg, K., Khan, F.R., Selck, H., Palmqvist, A., Banta, G.T., Daley, J., Sano, L Duhaime, M.B., 2015. Microplastics: addressing ecological risk through lessons learned. Environ. Toxicol. Chem. 34, 945-953.

Tanaka, K., Takada, H., Yamashita, R., Mizukawa, K., Fukuwaka, M.A., Watanuki, Y. 2013. Accumulation of plastic-derived chemicals in tissues of seabirds ingesting marine plastics. Mar. Pollut. Bull. 69, 219-222.

Teuten, E.L., Rowland, S.J., Galloway, T.S., Thompson, R.C., 2007. Potential for plastics to transport hydrophobic contaminants. Environ. Sci. Technol. 41, 7759-7764.

Thompson, R.C., Olsen, Y., Mitchell, R.P., Davis, A., Rowland, S.J., John, A.W.G., McGonigle, D., Russell, A.E., 2004. Lost at sea: where is all the plastic? Science 304, 838-838.

Tolls, J., 2001. Sorption of veterinary pharmaceuticals in soils: A review. ES T (Environ. Sci. Technol.) 35, 3397-3406.

Wang, F., Shih, K.M., Li, X.Y., 2015. The partition behavior of perfluorooctanesulfonate (PFOS) and perfluorooctanesulfonamide (FOSA) on microplastics. Chemosphere 119, 841-847.

Wu, C., Zhang, K., Huang, X., Liu, J., 2016. Sorption of pharmaceuticals and personal care products to polyethylene debris. Environ. Sci. Pollut. Control Ser. 23 (9), 8819-8826.

Weber, W.J., Morris, J.C., 1962. Advances in water pollution research: removal of biologically resistant pollutant from waste water by adsorption. In: International Conference on Water Pollution Symposium, vol. 2, pp. pp231-266. Pergamon, Oxford.

Zhang, H., Zhou, Q., Xie, Z., Zhou, Y., Tu, C., Fu, C., Mi, W., Ebinghaus, R., Christie, P., Luo, Y., 2018. Occurrences of organophosphorus esters and phthalates in the microplastics from the coastal beaches in north China. Sci. Total Environ. 616-617, 1505-1512.

Zhang, Q.Q., Ying, G.G., Pan, C.G., Liu, Y.S., Zhao, J.L., 2015. Comprehensive evaluation of antibiotics emission and fate in the river basins of China: source analysis, multimedia modeling, and linkage to bacterial resistance. Environ. Sci. Technol. 49, 6772-6782.

Zhang, R.J., Tang, J.H., Li, J., Cheng, Z.N., Chaemfa, C., Liu, D.Y., Zheng, Q, Song, M.K., Luo, C.L., Zhang, G., 2013. Occurrence and risks of antibiotics in the coastal aquatic environment of the Yellow Sea, North China. Sci. Total Environ. 450, 197-204.

Zhao, Y.P., Geng, J.J., Wang, X.R., Gu, X.Y., Gao, S.X., 2011. Adsorption of tetracycline onto goethite in the presence of metal cations and humic substances. J. Colloid Interface Sci. 361, 247-251.

Zhao, Y.P., Gu, X.Y., Gao, S.X., Geng, J.J., Wang, X.R., 2012. Adsorption of tetracycline (TC) onto montmorillonite: cations and humic acid effects. Geoderma 183, $12-18$.

Zhou, P., Huang, C., Fang, H., Cai, W., Li, D., Li, X., Yu, H., 2011. The abundance, composition and sources of marine debris in coastal seawaters or beaches around the northern South China Sea (China). Mar. Pollut. Bull. 62, 1998-2007.

Zhou, Q., Zhang, H., Fu, C., Zhou, Y., Dai, Z., Li, Y., Tu, C., Luo, Y., 2018. The distribution and morphology of microplastics in coastal soils adjacent to the Bohai Sea and the Yellow Sea. Geoderma 322, 201-208. 